\title{
UMA RECONSTITUIÇÃO DA ESTRATÉGIA FREUDIANA PARA A JUSTIFICAÇÃO DO INCONSCIENTE*
}

Fátima Caropreso e Richard Theisen Simanke

Fátima Caropreso
Pós-doutoranda
no Departamento
de Filosofia da
Universidade
Estadual de Campinas
(Unicamp).
Richard Theisen Simanke
Professor do
Departamento
de Filosofia e
Metodologia
das Ciências da
Universidade Federal
de São Carlos
(Ufscar).

Fátima Caropreso Pós-doutoranda no Departamento de Filosofia da Universidade Estadual de Campinas Ufscar)
RESUMO: A justificativa freudiana para a hipótese da existência do inconsciente é freqüentemente reduzida aos seus elementos empíricos ou a um argumento meramente heurístico. Trata-se aqui, primeiramente, de discutir a estratégia que Freud utiliza para incorporar o conceito de inconsciente em sua teoria; a seguir, de recapitular os diversos argumentos elaborados para justificá-lo; e, por fim, de reconstruí-los sistematicamente, procurando evidenciar os aspectos semânticos e conceituais do quadro teórico no qual as provas empíricas se inserem, assim como sua convergência com estratégias argumentativas contemporâneas de programas de investigação psicológica (as ciências da cognição, por exemplo) que também operam com a hipótese do inconsciente.

Palavras-chave: Freud, metapsicologia, inconsciente, representação, intencionalidade.

ABSTRACT: A reconstruction of Freud's argument for the justification of the unconscious. Freud's justification for the hypothesis of the unconscious has been often reduced to its empirical components or to purely heuristic arguments. First, this paper aims to discuss Freud's strategy in introducing the concept of unconscious in his theory; next, to recapitulate the various arguments that justify it; and finally, to systematically reconstruct them, in order to put in evidence the semantic and conceptual aspects of the theoretical framework where the empirical proofs are inserted, as well as its convergence with similar strategies of contemporary programs of psychological research (cognitive science, for instance) which also operate with the hypothesis of the unconscious.

Keywords: Freud, metapsychology, unconscious, representation, intentionality.

\footnotetext{
* Richard Theisen Simanke agradece ao CNPq pelo apoio concedido, sob a forma de Bolsa de Produtividade em Pesquisa, ao projeto Consciência e representação em psicanálise: alcance e limites da reflexão metapsicológica, do qual este artigo apresenta uma parte dos resultados.
} 
$\mathrm{N}$ o fim do século 19, quando Freud começa a desenvolver a hipótese de um psíquico inconsciente, a psicologia era, sobretudo, uma ciência da consciência - ou, ao menos, o projeto de uma tal ciência. As propostas para uma psicologia científica que surgem nesse período, como aquelas de Wundt, Brentano e William James, trabalharam sempre com a hipótese dessa identidade entre o mental e o consciente, tendo esses autores devotado passagens inteiras de seus principais trabalhos para demonstrar que estados mentais inconscientes eram uma impossibilidade de fato e de direito (JAMES, 1891/1978; BRENTANO, 1874/1944).

Em contraste com essa psicologia típica das últimas décadas do século 19, a psicologia cognitiva do final do século 20 assumiu a existência e a importância do domínio dos processos inconscientes para a explicação do pensamento e da ação, e o seu foco principal no processo de delimitação de seu objeto e de seu campo de investigação orientou-se para as representações mentais conscientes $e$ inconscientes (MANDLER, 1988). Freud foi, com certeza, uma figura de inegável destaque nessa transformação da psicologia de uma ciência da consciência em uma ciência das representações mentais. A maior contribuição de Freud para a psicologia moderna teria sido, assim, a separação por ele estabelecida entre representação e consciência: embora não tenha sido quem propriamente 'descobriu' o inconsciente - o termo já aparecia, de uma maneira ou de outra, na filosofia, na ciência e na medicina anteriores a ele (WHYTE, 1960; CAZETO, 2001) — a importância de Freud residiria sobretudo no fato de ter sido ele quem forneceu o argumento mais sistemático, persuasivo e fundamentado para essa mudança (WAKEFIELD, 1992).

Se levarmos em conta essas duas constatações - a importância contemporânea do conceito de inconsciente na investigação psicológica e a função histórica que Freud desempenhou na formulação e na fundamentação desse conceito parece justificar-se o esforço de resgatar os termos especificamente freudianos nos quais esse argumento pela existência e eficácia causal do inconsciente foi originariamente apresentado. Pode-se, assim, não apenas resgatar uma página decisiva do desenvolvimento histórico da psicologia científica (nem sempre apreendida em todo o seu alcance, tanto dentro quanto fora dos círculos psicanalíticos), como também dispor de um padrão para avaliar a relevância atual da reflexão metapsicológica freudiana e a dimensão da contribuição que ela ainda pode oferecer para a discussão epistemológica em torno das possibilidades da constituição da psicologia como ciência, sobretudo da perspectiva naturalista sustentada tanto por Freud quanto, mais recentemente, pela psicologia e pelas ciências da cognição em geral.

Portanto, pretendemos, nesse artigo, reconstituir e discutir qual teria sido a estratégia utilizada por Freud para incorporar em sua teoria metapsicológica o 
conceito de um inconsciente psíquico e retomar a forma geral dos argumentos por ele formulados, em diversos de seus textos, para justificá-lo. Feito isso, procuraremos fazer ressaltar a atualidade da estratégia argumentativa freudiana, ainda que numa discussão preliminar.

Em Nota sobre o conceito de inconsciente na psicanálise (FREUD, 1912/1982), encontramos uma distinção bastante precisa dos três grandes sentidos que a psicanálise atribui ao termo 'inconsciente’: o descritivo, o dinâmico e o sistemático.

O termo 'inconsciente' seria usado em sentido descritivo para designar um fato psíquico que, mesmo não estando presente na consciência ou não sendo percebido conscientemente, continue presente na vida mental. Esse é o sentido mais geral que pode ser atribuído ao termo 'inconsciente’, e ele pode ser legitimamente utilizado desde que se admita que, na ausência da consciência, as representações podem preservar a sua condição de fatos psíquicos.

No entanto, além da possibilidade das representações continuarem existindo, ainda que latentes na consciência, as manifestações neuróticas e o fenômeno da sugestão pós-hipnótica evidenciaram a Freud que as representações inconscientes preservam também sua capacidade de ação na vida psíquica, sendo capazes, inclusive, de influenciar a atividade mental consciente. Haveria, assim, um inconsciente psíquico e, além disso, efetivo (wirklich) e, com esse passo, avança-se de uma concepção descritiva do inconsciente para uma concepção dinâmica.

Nesse sentido dinâmico, o termo 'inconsciente' designaria pensamentos e representações que, apesar de sua intensidade e de sua capacidade de ação eficiente, permaneceriam afastados da consciência, insuscetíveis de se tornarem conscientes.

Mas haveria ainda um terceiro — e, segundo Freud, o mais importante sentido atribuído ao termo 'inconsciente' pela psicanálise: o sentido sistemático. A análise dos sonhos teria mostrado que os processos mentais inconscientes e insuscetíveis de se tornarem conscientes seriam governados por leis diferentes das que vigoram na consciência e estariam submetidos a um outro regime de funcionamento mental, possuindo, portanto, propriedades diversas daquelas da mente acessível à consciência. Isso exigiria que fossem considerados como pertencentes a uma categoria psíquica à parte. Essa constatação teria sido o que o levou Freud a introduzir em sua teoria a hipótese de um sistema inconsciente (das Unbewusste), com o objetivo de estabelecer quais são as características peculiares aos processos psíquicos insuscetíveis de se tornarem conscientes, que fariam com que eles passassem a constituir um grupo psíquico distinto.

Nos trabalhos publicados em vida de Freud, o conceito de 'psíquico inconsciente' aparece claramente formulado pela primeira vez em $A$ interpretação dos sonhos (1900); no entanto, é no Projeto de uma psicologia — texto escrito em 1895 e publicado postumamente em 1950 — que se encontra, de fato, a sua primeira formulação 
explícita: a idéia de um inconsciente dinâmico, tal como este seria definido em 1912, é aí introduzida na teoria freudiana, assim como o reconhecimento da possibilidade do uso do termo inconsciente em sentido descritivo. Já a idéia de um sistema inconsciente aparece pela primeira vez na carta a Fliess de 6 de dezembro de 1896 (FREUD, 1950/1975) e é plenamente desenvolvida no capítulo 7 de $A$ interpretação dos sonhos e no artigo metapsicológico O inconsciente (1915). Levando isso em conta, é preciso reconhecer que o conceito de inconsciente que se encontra formulado em 1900 possui uma história prévia de desenvolvimento, cuja consideração mostra-se imprescindível para sua compreensão.

\section{PRIMEIRA FORMULAÇÃO DO CONCEITO DE INCONSCIENTE PSÍQUICO}

Embora, como dissemos, a primeira formulação do conceito de inconsciente se encontre no Projeto de uma psicologia, ${ }^{1}$ para bem compreendermos qual foi a estratégia argumentativa utilizada por Freud para introduzi-lo, é necessário levar em consideração algumas idéias elaboradas alguns anos antes, em Sobre a concepção das afasias (1891). Nesse texto, Freud desenvolve uma reflexão que lhe vai permitir redefinir o conceito de representação, como resultado da crítica ali empreendida às teorias localizacionistas do funcionamento normal e patológico da linguagem. Ele propõe que a representação consistiria no concomitante psíquico de um processo cortical associativo, que corresponderia à última etapa de uma série de reorganizações sucessivas que a informação sensorial sofreria em seu caminho da medula ao córtex. Em oposição à hipótese sustentada pelo psiquiatra e neurologista alemão Theodor Meynert, Freud sustenta que não seria possível haver uma projeção ponto por ponto dos estímulos que chegam à periferia do sistema nervoso no córtex, de forma que os correlatos de nossas representações não podem ser cópias exatas da configuração dos estímulos periféricos. Freud argumenta, em primeiro lugar, que a própria anatomia do sistema nervoso impossibilitaria isso, uma vez que o número de fibras associativas que conecta a medula ao córtex seria menor do que aquele que conecta a periferia nervosa à medula, de modo que a informação sensorial teria necessariamente que ser reordenada ao longo de seu percurso aferente. Quando são recebidos no córtex cerebral, os estímulos sensoriais seriam integrados em um novo processo associativo, o qual consistiria no concomitante fisiológico da representação (CAROPRESO, 2002).

Freud ainda adota, em 1891, como hipótese sobre as relações entre o psíquico e o cerebral, a doutrina da concomitância, defendida por Jackson (1884/1958), de acordo

\footnotetext{
${ }^{1}$ Procuramos, em outros trabalhos (CAROPRESO, 2003, 2005, 2007; SIMANKE, 2005, 2007), discutir quando e como o conceito de um inconsciente psíquico passa a ser sistematicamente empregado por Freud, assim como em que medida a sua formulação inicial no Projeto de uma psicologia (FREUD, 1895/1950) se mantém no percurso posterior da teoria freudiana.
} 
com a qual os estados mentais e os estados nervosos ocorreriam paralelamente, não havendo interferência causal de um sobre o outro: para cada estado mental, haveria um estado correspondente no sistema nervoso; contudo o mental não surgiria como efeito desse processo físico, mas apenas o acompanharia. Segundo essa teoria, tudo que é mental — portanto, toda a representação — seria necessariamente consciente, de modo que a identificação tradicional entre o mental e o consciente é claramente mantida até esse momento.

Nos trabalhos sobre as neuroses publicados nos anos seguintes, podemos observar que essa identificação entre o mental e o consciente começa a ser questionada (CAROPRESO, 2003); não obstante, é apenas no Projeto de uma psicologia que ela será explicitamente abandonada. Nesse texto, em vez de fazê-la corresponder à totalidade do psíquico, Freud redefine a consciência como algo restrito e posterior em relação aos processos representacionais que, em seu conjunto, constituem a mente. Essa independência do psíquico em relação à consciência é claramente afirmada:

“Temos tratado os processos psíquicos como algo que pudesse prescindir desse conhecimento dado pela consciência, algo que existe independentemente de uma tal consciência. [...] Se não nos deixamos desconcertar por isso, segue-se desse pressuposto que a consciência não fornece um conhecimento nem completo, nem seguro dos processos neuronais; deve-se, em primeiro lugar, considerá-los em toda a extensão como inconscientes e deve-se inferi-los como outras coisas naturais.” (FREUD, 1895/1987, p.400, grifos nossos)

O modelo teórico do aparelho neuronal desenvolvido por Freud no Projeto descreve processos que ocorrem no sistema nervoso e que podem, em princípio, ser relacionados a regiões anatômicas do cérebro. Para poder incorporar em sua teoria a noção de um inconsciente psíquico, Freud passa, em 1895, a considerar como psíquicos aqueles processos cerebrais que, em 1891, se definiam como sendo apenas os concomitantes fisiológicos do mental. A passagem mencionada aqui dá a entender que os processos neuronais envolvendo o sistema de memória psi, descrito por Freud no Projeto, são genuinamente considerados como o psíquico e não apenas como seus correlatos, ao contrário do que sustentam alguns (SOLMS \& SALING, 1986; STRACHEY, 1975): em nenhum momento do Projeto, Freud diz estar formulando uma teoria acerca dos correlatos neurais do psíquico, mas sim deixa claro que os processos envolvendo quantidades e neurônios que ocorrem nos sistemas psi são processos efetivamente psíquicos e que estes são, ao mesmo tempo, independentes da consciência.

Os processos associativos do sistema psi seriam, assim, as próprias representações, e não mais apenas seus concomitantes fisiológicos, como havia sido 
sustentado em Sobre a concepção das afasias; esses processos, no entanto, seriam totalmente independentes da consciência, a qual poderia ou não se acrescentar a uma parte dos mesmos. De fato, ao comentar a relação da sua teoria da consciência com as demais, Freud afirma:

“Segundo uma teoria mecanicista avançada, a consciência é um mero acessório dos processos fisiológico-psíquicos, cuja supressão não alteraria nada no decurso psíquico. Segundo uma outra doutrina, a consciência é o lado subjetivo de todo acontecimento psíquico e, assim, inseparável do processo mental fisiológico. Entre ambas situa-se a doutrina aqui desenvolvida. Consciência é aqui o lado subjetivo de uma parte dos processos físicos no sistema nervoso - a saber, os processos ômega - e a supressão da consciência não deixa inalterado o acontecimento psíquico, mas inclui em si a supressão da contribuição de ômega." (FREUD, 1895/1987, p.403-4)

A consciência seria, portanto, o lado subjetivo dos processos do sistema ômega, mas não os próprios processos ômega. Mas o que significa ser o lado subjetivo de tais processos? Freud não é nada claro quanto a isso. Em uma outra passagem do Projeto, ele afirma que não se pode explicar como os processos de ômega fazem surgir a consciência e que ele tentará apenas descrever os processos neuronais paralelos aos fenômenos conscientes. A seguinte consideração no Esboço de psicanálise parece ser uma das mais elucidativas sobre a relação entre a consciência, o inconsciente e os processos nervosos:

\begin{abstract}
"Muitos, dentro e fora da ciência, satisfazem-se com assumir que apenas a consciência é psíquica; nesse caso, nada resta para a psicologia, a não ser discriminar, dentre os fenômenos psíquicos, entre percepções, sentimentos, processos de pensamento e volições. Concorda-se, em geral, no entanto, que esses processos conscientes não formam seqüências ininterruptas, completas em si mesmas; não há assim alternativa, a não ser assumir que há processos físicos ou somáticos concomitantes aos psíquicos, que devemos necessariamente reconhecer como mais completos que as seqüências psíquicas, já que alguns deles têm processos conscientes paralelos, mas outros não. Assim sendo, é claro que se torna plausível dar ênfase, em psicologia, a esses processos somáticos, reconhecer neles a verdadeira essência do psíquico e buscar alguma outra abordagem para os processos conscientes." (FREUD, 1940a/1975, p.157-8)
\end{abstract}

Segundo o que Freud afirma nessa passagem, os fenômenos conscientes seriam paralelos aos processos neuropsíquicos que constituiriam o inconsciente. Ele se vale igualmente do termo 'concomitante', que alude, como vimos, à doutrina de Jackson. Isso sugere que, para incorporar a noção de uma mente 
inconsciente em sua teoria, Freud teria deslocado a relação de concomitância que, em 1891, ele propusera existir entre uma parte dos processos nervosos e o psíquico - para entre os processos psíquicos inconscientes e os conscientes. Os processos nervosos, que eram primeiramente concebidos como os concomitantes fisiológicos do psíquico, seriam então identificados ao psíquico inconsciente, e a série mental paralela, que antes correspondia a todo o psíquico, passaria a corresponder a apenas uma parte deste, isto é, à sua parte consciente. Portanto, a mente inconsciente consistiria em processos nervosos, alguns dos quais teriam fenômenos conscientes paralelos e outros não. Esses fenômenos conscientes paralelos aos processos psíquicos inconscientes seriam também processos materiais, ou Freud teria trazido uma espécie de dualismo de substâncias para dentro do campo do psíquico? Seria possível concluir, a partir dessas observações, que uma parte do psíquico seria material — o inconsciente - e outra seria imaterial - a consciência?

É difícil encontrar uma resposta para essas questões nas manifestações explícitas de Freud. A passagem citada é das que fornece mais elementos nesse sentido, mas está longe de ser conclusiva, e esse ponto terá que ser discutido em outro lugar (ver CAROPRESO, 2006). O problema em foco é o que justifica essa expansão do campo do psíquico para além das fronteiras da consciência. Em vários momentos de sua obra, Freud elabora diversas justificativas para a suposição de um psíquico inconsciente, algumas das quais serão examinadas na continuidade.

\section{A JUSTIFICATIVA DO CONCEITO DE INCONSCIENTE}

Em O inconsciente (1915), Freud argumenta que a identificação entre mente e consciência não pode ser justificada, em primeiro lugar, porque ela consistiria em uma "convenção inadequada”: algumas doutrinas filosóficas e psicológicas teriam estabelecido convencionalmente que o psíquico é o consciente. Contudo, prossegue Freud, essa convenção não é adequada, porque ela, antes de tudo, “superestima sem fundamentação visível o papel da consciência” (FREUD, 1915b/1982, p.127). Ao contrário, a experiência clínica com as neuroses lhe teria sugerido que há processos psíquicos para além da consciência, processos com todas as características de uma representação que, não obstante, permanecem afastados da consciência, inacessíveis a ela e, mesmo assim, capazes de influir sobre a atividade mental consciente.

A partir disso, Freud conclui que a identificação convencional do mental com o consciente não pode ser sustentada, uma vez que se trata de uma convenção que se revelou contraproducente e incapaz de fazer jus aos dados da observação. Parece legítimo, portanto, abandoná-la e substituí-la por uma outra que pareça se adequar mais aos fatos ou ser mais fecunda do ponto de vista explicativo. 
Diante disso, Freud autoriza-se a assumir que o psíquico seja mais amplo do que a consciência e que esta última seja algo que possa vir a se acrescentar a uma pequena parte das nossas representações: “a psicanálise [...] tem que considerar a consciência como uma qualidade do psíquico que pode se apresentar junto a outras qualidades ou estar ausente" (FREUD, 1923/1982, p.283).

Em síntese, se as observações clínicas mostraram que há na mente processos que parecem possuir todas as características de uma representação, mas permanecem inconscientes, e que os dados conscientes são lacunares e não podem ser totalmente compreendidos sem a suposição de processos mentais inconscientes, então a hipótese de que toda representação deva ser consciente não parece mais se sustentar, uma vez que a vinculação exclusiva entre a representação e a consciência não passaria de uma mera convenção, a qual só se justifica pela sua potencialidade explicativa. Tampouco seria possível afirmar que essas representações afastadas da consciência permanecessem nesse estado apenas por serem pouco intensas, o que descartava a idéia de que haveria apenas uma diferença de intensidade entre o psíquico suscetível e o insuscetível de consciência. As neuroses teriam mostrado que, ao contrário, representações excessivamente intensas, como aquelas que estão na origem dos sintomas podem permanecer insuscetíveis de se tornarem conscientes. Em várias ocasiões, Freud chama a atenção para fatos como esses. Por exemplo, em $\mathrm{O}$ eu e 0 isso, ele afirma:

“Para a maioria daqueles com formação filosófica, a idéia de um psíquico que não seja também consciente é tão inconcebível, que lhes parece absurda e recusável por mera lógica. Creio que isso resulta apenas de que nunca tenham estudado os relevantes fenômenos da hipnose e do sonho, que — sem nenhuma referência ao patológico - impõem essa concepção. Contudo, sua psicologia da consciência é também incapaz de solucionar os problemas do sonho e da hipnose." (FREUD, 1923/1982, p.283)

Na continuação desse mesmo texto, ao comentar que, mesmo fora da consciência, as representações continuam existindo de forma latente, Freud afirma:

“Os filósofos, sem dúvida, objetariam: 'Não, o termo inconsciente não tem aqui nenhuma aplicação; enquanto a representação se encontrava em estado de latência, ela não era de modo algum algo de psíquico'. Se já neste ponto os contradisséssemos, cairíamos em uma querela de palavras, com a qual não se ganharia nada. No entanto, chegamos ao termo ou conceito de inconsciente por outro caminho: pelo tratamento de experiências nas quais a dinâmica psíquica desempenha um papel. Contatamos - isto é, tivemos que supor — que existem representações ou processos mentais muito intensos [...] que podem ter todas as conseqüências para a vida 
psíquica que as demais representações têm, inclusive conseqüências que podem novamente se tornar conscientes como representações, mesmo que elas mesmos não se tornem conscientes." (FREUD, 1923/1982, p.283-4)

Freud argumenta, então, ter sido levado a concluir, a partir da sua experiência clínica, que a restrição do mental ao consciente não possui fundamentação nem justificação suficiente, ao contrário da suposição de que haja um inconsciente psíquico. Em O inconsciente, ele alegara ainda um segundo motivo pelo qual a identificação do psíquico ao consciente seria uma convenção inadequada: além de superestimar sem fundamentação visível o papel da consciência, essa identificação restringiria em muito o campo da investigação psicológica e "nos precipitaria nas insolúveis dificuldades do paralelismo psicofísico" (FREUD, 1915b/1982, p.126-7). A consciência, como disse Freud numerosas vezes, é lacunar, no sentido de que não contém todos os elementos para a explicação dos fenômenos que aí ocorrem: estes últimos, além de corresponderem a apenas parte do psíquico, apresentam-se como determinados por processos inconscientes e, muitas vezes — sobretudo no caso das manifestações psicopatológicas, mas não apenas nelas —, só podem ser compreendidos tendo-se em vista essa determinação. Uma psicologia que lidasse apenas com a consciência não poderia, assim, explicar uma série de manifestações psíquicas, tais como os sintomas neuróticos, os sonhos e os atos falhos, pois a compreensão destes não poderia prescindir da referência ao inconsciente. Além disso, tal psicologia da consciência não poderia configurar-se como uma ciência natural:

"Enquanto que a psicologia da consciência nunca foi além daquelas seqüências lacunares, que dependem evidentemente de alguma outra coisa, o outro ponto de vista, que sustenta que o psíquico é em si inconsciente, permitiu à psicologia assumir seu lugar como uma ciência natural como qualquer outra. Os processos de que se ocupa são em si tão incognoscíveis quanto aqueles com que lidam outras ciências, química e física, por exemplo; mas é possível estabelecer as leis a que obedecem e acompanhar, sem interrupção, por longos trechos, suas relações mútuas e suas interdependências - em suma, chegar ao que se pode descrever como uma 'compreensão' do campo de fenômenos naturais em questão.” (FREUD, 1940a/1975, p.158)

Para Nagel (1976), Freud parece ter chegado à suposição de um psiquismo inconsciente por um raciocínio que parte da constatação da impossibilidade de construir uma ciência psicológica que se ocupe apenas da consciência, devido ao caráter fragmentário desta última, no sentido de não constituir um sistema de relações causais suficientes e completas. Essas lacunas causais poderiam, é 
verdade, ser preenchidas pela suposição de um sistema de processos fisiológicos (físicos) inconscientes e psíquicos conscientes, no qual os segundos apareceriam como efeitos dos primeiros, de forma que todo fenômeno consciente pressuporia um processo físico como causa, mas nem todo processo físico se traduziria, necessariamente, num fenômeno de consciência. Contudo, segundo esse autor, uma reflexão mais cuidadosa sugeriu a Freud que:

“[...] talvez seja um erro identificar o mental com esses efeitos conscientes, e que ele deveria ser identificado com os próprios processos físicos [...]: já que a natureza verdadeira dos processos mentais que se apresentam à consciência é física, com a consciência sendo apenas uma qualidade adicional deles, não pode haver objeção em também descrever como mentais esses processos intermediários, ocorrendo no mesmo sistema físico, os quais não se apresentam à consciência apesar de eles, em muitos detalhes, poderem ser física e funcionalmente semelhantes aos que se apresentam a ela." (NAGEL, 1976, p.27)

Retornando ao artigo metapsicológico sobre o inconsciente, Freud argumenta ali que se, por um lado, a restrição do psíquico ao consciente é uma convenção inadequada, por outro, é possível acrescentar "que a suposição do inconsciente é necessária e legítima e que possuímos múltiplas provas da existência do inconsciente" (FREUD, 1915b/1982, p.125, grifos do autor). Mais uma vez, ele apela para o argumento de que essa suposição é necessária, porque os dados da consciência seriam lacunares e não poderiam ser compreendidos sem a suposição de processos psíquicos inconscientes. O fato de tal suposição torná-los compreensíveis - ou seja, de ela preencher as lacunas detectadas na determinação dos atos conscientes e lhes atribuir um sentido — torná-la-ia legítima.

Além disso, prossegue Freud, a hipótese do inconsciente pode também ser considerada legítima, porque, para adotá-la, não seria necessário nos afastarmos de nosso modo habitual de pensar, que se assume espontaneamente como correto. A cada um de nós, a consciência forneceria somente o conhecimento dos nossos próprios estados mentais. A idéia de que outro ser humano possuísse também consciência seria uma inferência, um raciocínio a que se chegaria por simples analogia, com base nas manifestações e ações desse outro, com o objetivo de tornar compreensível sua conduta. Sendo essa a única maneira de compreender o comportamento alheio, o que a psicanálise estaria propondo consistiria apenas em que esse mesmo raciocínio se voltasse para si mesmo, com a diferença de que as pessoas não possuem normalmente nenhuma inclinação espontânea para isso. Agindo dessa maneira, todos os atos e manifestações que o sujeito notasse em si e não conseguisse relacionar com o restante de sua vida psíquica poderiam ser julgados como se pertencessem a uma outra pessoa e esclarecidos com a atribuição 
a esse "outro" de uma vida psíquica própria. Com esse raciocínio, chegar-se-ia naturalmente à suposição de um inconsciente, de uma atividade psíquica que permanecesse excluída da consciência, embora a influenciasse. Diz Freud: “A suposição psicanalítica da atividade psíquica inconsciente parece-nos, por um lado, como uma continuação do animismo primitivo, que por toda parte refletia simulacros de nossa consciência [...]” (FREUD, 1915b/1982, p.130).

A suposição do inconsciente poderia ainda ser provada, argumenta Freud, uma vez que, com base nela, fora possível construir um procedimento técnico capaz de influenciar com êxito o curso dos processos conscientes: esse êxito clínico e terapêutico poderia ser tomado como mais uma prova da existência do inconsciente. Também os experimentos hipnóticos — em particular, o fenômeno da sugestão pós-hipnótica — manifestariam, de maneira palpável, a existência e o modo de ação do inconsciente.

\section{RECONSTRUINDO O ARGUMENTO FREUDIANO}

No entanto, os argumentos apresentados até aqui poderiam dar a impressão de que Freud estaria simplesmente substituindo uma convenção por outra — a que identifica mente e consciência pela que define como mentais os processos cerebrais subjacentes às manifestações conscientes — movido basicamente por considerações de ordem pragmática: em primeiro lugar, a fecundidade heurística que permite tornar inteligíveis fenômenos que não o seriam de outra forma e, além disso, configurar a psicologia como uma ciência da natureza; em segundo, a eficiência técnica do método de intervenção construído sobre essa hipótese, a qual, em sentido inverso, forneceria evidências suplementares para a sua comprovação, dando margem à crítica de que se estaria incorrendo num raciocínio circular. Restariam, então, as provas empíricas, que, além de poderem igualmente ser colocadas sob suspeita pelo fato de serem obtidas pela aplicação desse mesmo método, são, por si sós, inconcludentes, uma vez que as observações alegadas sempre admitiriam, em princípio, uma explicação ou uma descrição em outros termos. Assim, para se poder sustentar a solidez do argumento freudiano e sua redefinição dos processos cerebrais subjacentes aos fenômenos de consciência como representações (CAROPRESO, 2006) faz-se necessário reconstruir esse argumento de forma sistemática e explicitar suas partes constituintes e suas relações, de modo a poder distinguir entre seus componentes conceituais e empíricos e, sobretudo, estabelecer a dependência dos segundos com relação aos primeiros, no sentido de que o valor comprobatório das supostas provas empíricas da existência do inconsciente depende do conjunto da trama conceitual do argumento em que se inserem.

Wakefield (1992) sistematiza a justificativa freudiana para a suposição de estados mentais inconscientes, além de ressaltar o quanto Freud é atual do 
ponto de vista da psicologia cognitiva que se desenvolve no último terço do século 20, sustentando que, reconstruído em termos modernos, o argumento freudiano para justificar a hipótese do inconsciente seria exatamente o mesmo usado pelos cognitivistas contemporâneos (SHEVRIN, 1992; WEINBERGER e WEISS, 1997). No que se segue, utilizamos sua reconstrução como fio condutor de nossa análise.

O primeiro passo, segundo esse autor, seria o fato de Freud ter, de modo geral, concebido a mente como um sistema de estados intencionais (desejos, impulsos, temores, propósitos, etc.) dinamicamente integrados: ao considerar a intencionalidade — no sentido originariamente definido por Brentano (1874/1944), que aponta para o fato de esses estados se referirem a algo, seja real, virtual ou possível, que lhes é exterior e que eles representam de alguma maneira — como a característica distintiva do mental, ao invés da consciência, Freud estaria se dando os meios para justificar a hipótese do inconsciente, desde que pudesse demonstrar que essas propriedades intencionais podem ser realizadas na ausência de uma apreensão consciente, na contramão de demonstrações clássicas da identidade necessária entre consciência e intencionalidade, como as de Brentano e James mencionadas aqui. É, pois, o argumento freudiano a favor da existência de estados intencionais e representacionais inconscientes que precisa ser resgatado.

Esquematicamente, esse argumento pode ser repartido em três momentos, dos quais os dois primeiros são estritamente conceituais. A primeira parte do argumento envolve uma questão que é, ao mesmo tempo, semântica e conceitual, a saber, se o termo 'mental' significa necessariamente 'consciência' e se se incorreria ou não numa contradição em termos ao considerar algo como simultaneamente 'mental' e 'inconsciente'. Como vimos, Freud considera essa identificação como uma mera convenção; resta explicitar o fundamento dessa invectiva freudiana. Wakefield recorre à filosofia da linguagem e do conceito para argumentar que é necessário distinguir entre a significação de um termo que designa uma espécie natural (natural kind) e a essência dessa espécie. ${ }^{2}$ A definição da essência de uma espécie natural (QUINE, 1969; HACKING, 1990) caberia à investigação científica, não se reduzindo a uma questão puramente semântica; por outro lado, antes de se possuir um conhecimento confiável sobre a essência de alguma coisa, a significação do termo que a designa só poderia ser estabelecida por meio de observações empíricas, que ensaiariam uma definição a partir de suas manifestações mais evidentes, até que novas observações permitissem

\footnotetext{
${ }^{2}$ Utilizamos o conceito de natural kind no sentido usual que ele tem em epistemologia, quando designa tanto um agrupamento não artificial de coisas, eventos, seres, etc., quanto a(s) propriedade(s) que os membros desse agrupamento têm em comum e que faz(em) com que este consista em um conjunto real, e não numa reunião arbitrária ou devida apenas aos critérios de classificação empregados.
} 
ampliar e precisar o sentido inicial do conceito. Assim, para lançar mão de um exemplo elementar, o termo 'água’ foi inicialmente definido por referência ao líquido transparente e incolor dos rios, lagos, chuva, etc. Mesmo antes de se descobrir qual é a essência da água, foi possível inferir, mediante novas observações (do congelamento, do degelo, etc.) que coisas sólidas como o gelo e coisas opacas e brancas como a neve também eram água. Quando, depois, a química descobriu que a estrutura molecular da água é H2O, isso permitiu compreender as diversas manifestações daquela mesma substância, mas não se poderia dizer que ‘água' passou, com isso, a significar H2O. Caso contrário, seria preciso admitir que, até essa descoberta, o sentido do termo era desconhecido, quando o que se desconhecia era a essência daquilo que esse termo designava. Uma vez que se conhece que H2O é a essência da água, se forem encontradas outras coisas que possuam essa mesma estrutura molecular, elas também poderão ser chamadas de água, independentemente das propriedades que se revelem à observação. Portanto, decidir quais coisas no mundo podem ou não ser chamadas de água é uma questão que deve ser respondida a partir da investigação científica, e não, a priori, por definição ou convenção.

Da mesma forma, o termo 'mental' teria sido definido primeiramente por referência a pensamentos, desejos e crenças conscientes, que são suas manifestações empíricas mais evidentes; contudo, como se viu, isso não implicaria que só pode ser considerado mental aquilo que é consciente, assim como não são apenas as substâncias líquidas e transparentes que puderam ser consideradas como sendo água, embora esse último termo tenha sido definido inicialmente por referência a elas. Em suma, 'mental' não significaria necessariamente 'consciente', da mesma maneira que ‘água' não significa necessariamente 'líquido e transparente’. Mesmo antes de se descobrir qual é a essência do que é significado por esse ou por aquele termo, seria possível inferir, a partir de outras observações, que há outras manifestações daquela mesma essência desconhecida que também podem ser assim nomeadas. Se os fatos empíricos assim observados revelarem que há fenômenos com as mesmas características daquilo que se chama de mental e que, contudo, não são conscientes, não haveria nenhum problema em estender a eles a significação desse termo, assim como se mostrou legítimo considerar o gelo como água embora ele não seja líquido, mesmo antes de se conhecer a estrutura molecular da substância água. ${ }^{3}$ As observações em que Freud baseou sua hipótese do inconsciente — os sintomas neuróticos, lapsos, sonhos, etc. -

3. A analogia da água tem sido utilizada desde Stuart Mill (1843/1979), pelo menos, na apresentação da sua concepção da causalidade, em que surge pela primeira vez a idéia de "propriedades emergentes". Os autores em que Wakefield (1992) se baseia a retomam também (PUTNAM, 1975; KRIPKE, 1980). 
seriam, assim, comparáveis, no exemplo proposto, às observações do congelamento e do degelo, fornecendo evidências de que a mente não é necessariamente consciente, assim como aquelas evidenciaram que a água não é necessariamente líquida e transparente. Não haveria, portanto, nenhum problema conceitual ou de princípio que impedisse, em princípio, a suposição de uma mente inconsciente. A solução definitiva para o problema de se é ou não justificável fazê-lo é outra questão que deve ser resolvida pela investigação científica, pois se trata de uma questão sobre a natureza da coisa em foco, e não de uma questão meramente semântica. Quando Freud afirma que a identificação do psíquico ao consciente consiste em uma convenção que se revelou inadequada e deve ser abandonada diante das novas evidências, ele estaria desenvolvendo essa primeira etapa conceitual da argumentação.

Considerada a partir dessa perspectiva, a célebre passagem na abertura do artigo metapsicológico sobre as pulsões pode ser vista sob uma nova luz, quando se revela que a concepção freudiana sobre o modo de formulação dos conceitos científicos é compatível com a que foi aqui apresentada, e não expressa um mero convencionalismo motivado por considerações exclusivamente heurísticas:

“Elas [as idéias que precedem os conceitos básicos de uma ciência] devem, de início, trazer consigo certo grau de indeterminação; não se pode pensar numa delimitação clara de seu conteúdo. Enquanto se encontram nesse estado, entendemo-nos a respeito de seu significado pela referência repetida ao material empírico do qual parecem derivar, mas que, na verdade, lhes está submetido. Elas possuem, assim, estritamente falando, o caráter de convenções, mas tudo depende de que não sejam escolhidas arbitrariamente, mas sim determinadas por relações significativas com o material empírico, relações que acreditamos pressentir mesmo antes que se possa conhecê-las e demonstrá-las." (FREUD, 1915a/1982, p.81)

Estabelecido que a expressão 'mente inconsciente' não é necessariamente uma contradição em termos, o segundo passo da argumentação seria mostrar que a suposição da existência do que essa expressão designa é teoricamente possível. Para isso, em primeiro lugar, é preciso formular uma hipótese sobre a natureza essencial do mental e, então, demonstrar que coisas com essa essência podem ser inconscientes. É claro que, caso se parta do pressuposto de que a consciência é a essência do mental, supor que há mente inconsciente seria contraditório; Freud argumenta, como se viu, que a consciência não constitui a essência do mental, mas apenas uma qualidade que pode ou não se acrescentar a uma pequena parte do mesmo. Wakefield (1992) propõe que a essência do mental, para Freud embora este não se exprima exatamente nesses termos - é a representacionalidade dos estados cerebrais e que esta é uma propriedade que pode ser perfeitamente apli- 
cada a estados cerebrais não conscientes. De fato, desde o Projeto de uma psicologia, Freud trabalha com a hipótese de que o mental é sobretudo o representacional e de que a consciência é apenas uma qualidade que pode se acrescentar a uma representação.

Ora, a postulação de uma essência é, em grande parte, a postulação de uma causa subjacente àquele fenômeno manifesto a partir do qual a categoria foi selecionada e descrita em primeiro lugar - por exemplo, no sentido em que as propriedades químicas do composto $\mathrm{H} 2 \mathrm{O}$ explicam as propriedades sensíveis da água, do gelo, das mudanças de estado, etc. Da mesma forma, o movimento dos elétrons é considerado a essência da eletricidade, porque os fenômenos que primeiramente foram usados para nomear a eletricidade são, em última instância, explicáveis pelo processo subjacente do movimento de elétrons. Seguindo o esquema proposto, uma vez que o fluxo de elétrons tenha sido estabelecido como a essência do fenômeno especificado, qualquer outro fenômeno que se possa demonstrar como causado por esse fluxo pode ser legitimamente categorizado como eletricidade. Mas, mesmo antes da essência ser conhecida, um fenômeno podia ser descoberto como fazendo parte da categoria eletricidade, a partir de evidências indiretas de que ele compartilha a mesma essência do fenômeno original. Segundo Wakefield (1992), Freud, assim como a maioria dos cientistas cognitivos atuais, teria acreditado que o fator explicativo relevante do mental é a estrutura representacional dos estados cerebrais, independentemente do estatuto consciente ou não desses estados. A consciência seria apenas algo que se pode acrescentar a um estado cerebral dotado dessa estrutura representacional. Esta última, por sua vez, é definida como a essência provisória do mental e, na medida que sua definição é independente do atributo da consciência, ela torna legítima a suposição de uma mente inconsciente.

Contudo, a natureza última da mente teria permanecido desconhecida para Freud, assim como permanece para os cientistas cognitivos contemporâneos (WAKEFILED, 1992): tanto um como os outros estariam cientes de que considerar a representacionalidade dos estados cerebrais como constituindo a essência do mental só pode ser uma postura provisória e que uma resposta definitiva a essa questão requereria uma especificação detalhada da natureza do sistema representacional do cérebro. Em nenhum dos casos, ter-se-ia ainda chegado a conhecer realmente a essência do mental, o que continuaria ainda na dependência da evolução do conhecimento científico. Seja como for, há igualmente evidências suficientes em Freud de que a atribuição a ele desse modo de raciocínio não seria arbitrária. Por exemplo, como Wakefield também comenta, Freud compara explicitamente o processo de formação dos conceitos psicanalíticos — no caso aqui, a própria definição do mental — com o que acontece em outras ciências da natureza, como a física. Assim, diante da pergunta sobre qual seria a essência 
do psíquico, o psicólogo (ou o psicanalista) responderia da mesma forma hoje como o físico teria respondido há algum tempo atrás:

“Se alguém pergunta o que 'o psíquico' realmente significa, é fácil responder enumerando seus constituintes: nossas percepções, idéias, memórias, sentimentos e atos de vontade - tudo isso faz parte do que é psíquico. Mas se o interlocutor vai em frente e pergunta se não há alguma qualidade comum possuída por todos esses processos que torne possível nos aproximarmos da natureza ou, como as pessoas às vezes dizem, da essência do psíquico, seria então mais difícil dar uma resposta. Se uma pergunta análoga fosse feita a um físico (por exemplo, acerca da essência da eletricidade), sua resposta, até bem recentemente, teria sido: 'A fim de explicar certos fenômenos, assumimos a existência de forças elétricas que estão presentes nas coisas e emanam delas. Estudamos esses fenômenos, descobrimos as leis que os governam e ainda lhes damos um uso prático. Provisoriamente, isso nos satisfaz. Não conhecemos a natureza da eletricidade. Talvez a descubramos mais tarde, quando nosso trabalho avançar. É preciso admitir que o que ignoramos é justamente a parte mais importante e interessante da coisa toda, mas isso não nos perturba por hora. É simplesmente assim que as coisas acontecem nas ciências naturais." (FREUD, 1940b/1975, p.282, grifos do autor)

Este teria sido, então, o raciocínio freudiano para demonstrar que seria teoricamente possível conceber uma mente inconsciente, cujo ponto central reside no pressuposto que considera, ainda que provisoriamente, a essência do mental como consistindo nas características intrinsecamente intencionais e representacionais dos estados cerebrais, as quais podem se realizar na ausência da consciência, sem incorrer em contradição. Assume-se, igualmente, que essa essência do mental só poderá ser considerada como plenamente elucidada quando for possível especificar as características dos estados cerebrais que lhes conferem sua intencionalidade e o caráter representacional que lhes é inerente. Mas, mesmo antes de se alcançar esse esclarecimento, tornar-se-ia, por essa via, legítimo supor que a consciência não é uma propriedade essencial à mente e, portanto, que é legítima a suposição de uma mente inconsciente.

A terceira etapa da argumentação freudiana para justificar a existência de estados mentais inconscientes seria, então, estabelecer que esses estados não são apenas teoricamente possíveis, mas que eles existem de fato. Na medida que a psicanálise constituiu-se como uma disciplina clínica e voltada, por isso, para a investigação empírica do campo de fenômenos que delimitou para si, é compreensível que este tenha sido, desde o princípio, a faceta mais evidente da argumentação desenvolvida por Freud: desde o início de suas investigações sobre as neuroses, ele se deparou com fenômenos mentais que puderam ser tomados 
como evidências factuais da existência de processos inconscientes, cuja natureza psíquica foi-se impondo pouco a pouco à elaboração teórica, como se recapitulou acima: de início, a sugestão pós-hipnótica e os sintomas neuróticos e, depois, os sonhos, os atos falhos, as produções artísticas, etc. Wakefield (1992) comenta como os estudos de caso elaborados por Freud podem ser considerados como longos argumentos a favor da necessidade de se supor a ação de representações inconscientes na explicação do pensamento e do comportamento dos sujeitos. É verdade, portanto, que as evidências empíricas constituíram-se no ponto de partida de toda a investigação freudiana que acabou conduzindo à formulação da teoria psicanalítica do inconsciente, mas isso não nos deve levar a perder de vista que essas evidências são situadas, ponderada e minuciosamente, no contexto de um argumento complexo, não apenas sofisticado do ponto de vista conceitual, mas também atual na sua forma e na sua estratégia.

\section{CONSIDERAÇÕES FINAIS}

Freud, evidentemente, não apresenta sua argumentação da maneira sistemática como expusemos aqui, mas esses três níveis de argumentação apontados são, de fato, desenvolvidos, ainda que de maneira dispersa, ao longo de sua obra, sendo que o momento mais sistemático é o que pode ser encontrado no capítulo inicial de O inconsciente (1915). É fato que Freud dá muita ênfase em sua argumentação explícita ao fato de que a suposição de uma mente inconsciente é condição para que a psicologia possa se configurar como uma ciência natural - o que podemos chamar de uma justificativa heurística - e também desenvolve o que podemos chamar de uma justificação pragmática para a suposição do inconsciente, quando alega que a partir dela foi possível criar um procedimento clínico de intervenção eficaz. Essas justificações heurística e pragmática seriam, na verdade, desdobramentos da parte empírica da argumentação tal como esta se encontra na sistematização de Wakefield (1992) que serviu de base para aquela aqui apresentada. No entanto, como se discutiu acima, a maior visibilidade da etapa empírica do argumento freudiano corre o risco de obscurecer as etapas conceituais que lhe são logicamente anteriores e sem as quais as provas clínicas dificilmente poderiam ser consideradas conclusivas, o que, numa outra direção, justifica o esforço aqui empreendido em explicitá-las.

Por vezes, o reconhecimento do naturalismo psicológico freudiano, que fornece o contexto teórico no qual a teoria do inconsciente toma forma, parece, por si só, levar certos autores a concluir que a verificação dessa hipótese haveria de ser exclusivamente empírica e a atribuir a Freud essa intenção.

Examinemos apenas, para finalizar, um exemplo bem representativo dessa atitude que se procurou contestar aqui. Juranville (1984/1987) procura argumentar que a única demonstração viável da existência do inconsciente seria a sua 
dedução a partir da linguagem, tal como foi empreendida por Lacan, ao passo que Freud teria, em função de seus compromissos epistemológicos, enveredado pela via sem esperança da comprovação empírica — ou, até mesmo, num sentido bem amplo, experimental:

“O inconsciente é, portanto, em primeiro lugar, a hipótese do inconsciente. E é preciso tentar estabelecer a existência do inconsciente tal como se verifica uma hipótese. Apenas dois métodos são possíveis: pode-se proceder a uma verificação experimental, como se faz na química ou na biologia. [...] Também se pode tentar uma fundamentação ou uma dedução lógica a partir de uma verdade evidente, procedendo então através do raciocínio puro. [...] Sabemos que Freud pretendeu ser levado a confirmar a existência do inconsciente por meio do primeiro método. Mas ocorre que as provas de Freud jamais convenceram ninguém, senão aqueles que já estavam convencidos." (JURANVILLE, 1984/1987, p.21-2)

Deixando de lado a ingenuidade epistemológica dessa afirmação — que atribui à atitude das ciências naturais essa espécie de empirismo generalizado que excluiria qualquer consideração de ordem dedutiva ou conceitual - o que se observa aqui é a idéia de que Freud só poderia ter tentado uma demonstração exclusivamente empírica da hipótese do inconsciente, devido à impossibilidade de simplesmente conceber alguma outra alternativa, o que é, aliás, textualmente afirmado mais adiante: "Mas se, para Freud, o estabelecimento da hipótese do inconsciente deve efetuar-se como uma verificação experimental, é porque não poderia haver uma outra" (JURANVILLE, 1984/1987, p.28). A conseqüência esperada dessa linha de raciocínio é aquela que já foi mencionada acima: restringindo-se às provas empíricas, sempre inconcludentes quando se trata de estabelecer a natureza ou a essência da espécie em questão, as únicas justificativas que se poderiam alegar para a sustentação da hipótese do inconsciente seriam aquelas de ordem pragmática ou heurística, relacionadas apenas à utilidade do conceito, mas sem maiores implicações ontológicas. Assim:

“[...] se é verdade que as confirmações empíricas da existência do inconsciente conservam qualquer coisa de problemático, será que devemos renunciar à idéia de tal confirmação? Mas, nesse caso, o inconsciente seria não mais que uma hipótese, uma espécie de ficção útil, talvez, mas sem significação efetiva para o sujeito humano." (JURANVILLE, 1984/1987, p.30)

O que se procurou evidenciar neste trabalho é que o argumento freudiano para a existência do inconsciente é algo de mais complexo, nuançado e sofisticado na sua compreensão da natureza dos conceitos e das teorias científicas e de 
sua relação com os dados empíricos produzidos pela investigação. Considerado em todas as suas dimensões, esse argumento revela ainda uma atualidade até certo ponto surpreendente e uma afinidade com a atitude epistemológica de programas de pesquisa muito mais recentes que, tal como Freud, servem para mostrar que a aposta naturalista na investigação da subjetividade não implica recair num empirismo grosseiro, nem tampouco numa redução generalizada desse domínio às suas determinações físico-químicas ou qualquer coisa desse tipo, mas se apresentam, ao contrário, como uma estratégia filosófica e cientificamente fecunda para a constituição de uma ciência da mente.

Recebido em: 15/5/2007. Aprovado em: 13/7/2007.

\section{REFERÊNCIAS}

BRENTANO, F. (1874/1944) Psychologie du point de vue empirique. Paris: Aubier.

CAROPRESO, F. (2002) "Representação e consciência na obra inicial de Freud”. Dissertação de Mestrado, Universidade Federal de São Carlos.

(2003) As origens do conceito de inconsciente psíquico na teoria freudiana. Natureza Humana: Revista Internacional de Filosofia e Práticas Psicoterápicas, v.5, n.2, p.329-350.

(2005) A elaboração da concepção sistemática do inconsciente na primeira tópica freudiana. Fragmentos de Cultura, v.15, n.6, p.941-963.

. (2006) "A natureza do psíquico e o sentido da metapsicologia na psicanálise freudiana”. Tese de Doutorado, Programa de Pós-graduação em Filosofia, Universidade Federal de São Carlos.

. (2007) "O conceito de inconsciente psíquico: desenvolvimento e articulações conceituais”, in AYRES, S. e VASCONCELOS,

C. (orgs.) Ensaios de filosofia e psicanálise. Campinas: Mercado das Letras (no prelo).

CAZETO, S. J. (2001) A constituição do inconsciente em práticas clínicas na França do século XIX. São Paulo: Escuta.

FREUD, S. (1891) Zur Auffassung der Aphasien: eine Kritische Studie. Leipzig: Franz Deuticke.

. (1987) Gesammelte Werke. Frankfurt: Fischer Verlag.

(1895/1950) “Entwurf einer Psychologie”, Nachtragsband, p.387- 477. . (1982) Studienausgabe. Frankfurt: Fischer.

(1900) “Die Traumdeutung”, v. 2, 698p.

(1912) "Einige Bemerkungen über den Begriff des Unbewussten in der Psychoanalyse", v. 3, p.25-36.

(1915a) “Triebe und Triebschcksale”, v.3, p.75-102. 
(1915b) “Das Unbewusste”, v. 3, p.119-162.

(1923) “Das Ich und das Es”, v. 3, p.273-330.

. (1950/1975) Aus den Anfängen der Psychoanalyse. Frankfurt: Fischer.

(1975) The Standard Edition of the complete psychological works of Sigmund Freud. Londres: Hogarth Press.

(1940a) “An outline of psycho-analysis”, v. 23, p.141-207.

(1940b) “Some elementary lesson in psycho-analysis”, v. 23, p.279-286.

HACKING, I. (1990) "Natural kinds", in BARRETT, R. B. e GIBSON, R. (orgs.). Perspectives on Quine. Cambridge, MA: Blackwell.

JACKSON, J. H. (1884/1958) "Evolution and dissolution of the nervous system”, in TAYLOR, J. (org.). Select Writings of John Hughlings Jackson. New York: Basic Books.

JAMES, W. (1891/1978) “The principles of psychology”, in Great Books of Western World, v.53. London: Encyclopaedia Britannica Col.

JURANVILLE, A. (1984/1987) Lacan e a filosofia. Rio de Janeiro: Jorge Zahar.

KRIPKE, S. (1980) “The identity thesis”, in S. KRIPKE (org.). Naming and necessity. Oxford: Blackwell.

MANDLER, G. (1988) "Problems and directions in the study of consciousness”, in HOROWITZ, M. J. (ed.). Psychodynamics and cognition. Chicago: University Press.

NAGEL, T. (1976) "O antropomorfismo de Freud", in WOLLHEIM, R. (org.). Freud: uma coletânea de ensaios críticos. Rio de Janeiro: Artenova.

PUTNAM, H. (1975) “The meaning of meaning”, in H. PUTNAM (org.). Philosophical papers, v.2. Cambridge: Cambridge University Press.

QUINE, W. (1969) "Natural kinds", in Ontological reality and other essays. New York: Columbia University Press.

SHEVRIN, H. (1992) "The Freudian unconscious and the cognitive unconscious: identical or fraternal twins?”, in J. BARRON, J., EAGLE, M. N. \& D. L. WOLITZKY, D. L. (orgs.). Interface of psychoanalysis and psychology. Washington: American Psychological Association.

SIMANKE, R. T. (2005) Memória, afeto e representação: o lugar do "Projeto..." no desenvolvimento inicial da metapsicologia freudiana. Olhar, v.12/13, p.12-40.

(2007) Mente, cérebro e consciência nos primórdios da metapsicologia freudiana: uma análise do "Projeto de uma psicologia" (1895), v.1. São Carlos: EDUFSCar.

SOLMS, M. \& SALING, M. (1986) On psychoanalysis and neuroscience: Freud's attitude to the localizacionist tradition. International Journal of Psychoanalysis, v.67, p.397-416.

STRACHEY, J. (1975) “Editor's note to The Unconscious”, in The Standard Edition of the complete psychological works of Sigmund Freud, v. XIV, p.161-165. London: Hogarth Press.

STUART MILL, J. (1843/1979) “Sistema de lógica dedutiva e indutiva”, in Os pensadores: Jeremy Bentham, John Stuart Mill. São Paulo: Abril Cultural 
WAKEFIELD, J. C. (1992) "Freud and cognitive psychology: the conceptual interface”, in J. BARRON, J., EAGLE, M. N. \& D. L. WOLITZKY, D. L. (orgs.). Interface of psychoanalysis and psychology. Washington: American Psychological Association.

WEINBERGER, J. e WEISS, J. (1997) "Psychoanalytic and cognitive conceptions of the unconscious", in STEIN, D. (org.). Cognitive science and the unconscious. Washington and London: American Psychiatric Press.

WHYTE, L. L. (1960) The unconscious before Freud. New York: Basic Books.

Fátima Caropreso

fatimacaropreso@uol.com.br

Richard Theisen Simanke

richardsimanke@uol.com.br 